\title{
Laurent Dubreuil, L'état critique de la littérature
}

\section{Orlando Bonserio}

\section{(2) OpenEdition}

\section{Journals}

\section{Edizione digitale}

URL: http://journals.openedition.org/studifrancesi/7088

DOI: 10.4000/studifrancesi.7088

ISSN: 2427-5856

\section{Editore}

Rosenberg \& Sellier

\section{Edizione cartacea}

Data di pubblicazione: 1 septembre 2010

Paginazione: 424-425

ISSN: 0039-2944

\section{Notizia bibliografica digitale}

Orlando Bonserio, «Laurent Dubreuil, L'état critique de la littérature», Studi Francesi [Online], 161 (LIV | II) | 2010, online dal 30 novembre 2015, consultato il 13 janvier 2021. URL: http://

journals.openedition.org/studifrancesi/7088 ; DOI: https://doi.org/10.4000/studifrancesi.7088

Questo documento è stato generato automaticamente il 13 janvier 2021.

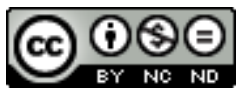

Studi Francesi è distribuita con Licenza Creative Commons Attribuzione - Non commerciale - Non opere derivate 4.0 Internazionale. 


\title{
Laurent Dubreuil, L'état critique de la littérature
}

\author{
Orlando Bonserio
}

\section{NOTIZIA}

LAURENT DUBREUIL, L'état critique de la littérature, Hermann éditeurs, Paris, 2009 («Savoir Lettres»), pp. 222.

1 La formazione di Laurent DUBREUIL ha avuto una forte impronta filosofica, oltreché letteraria, essendo stato - come si può leggere sulla sua homepage personale all'interno del sito dell'Università di Cornell - allievo di grandi maestri quali Jacques Derrida ed Umberto Eco. Un'impronta che è largamente rintracciabile all'interno di questo suo L'état critique de la littérature, nel quale la letteratura non viene trattata né come qualcosa di astratto, slegato dal mondo e dalle altre discipline e rinchiusa in se stessa, né come un sottoinsieme di altre scienze sociali o umane, bensì come uno strumento di indagine, esplorazione e connessione di queste dottrine e del mondo: «La littérature est plutôt l'épreuve des autres modes intellectifs et des savoirs instituées». Oltre a questo, l'interesse dell'autore per la letteratura è anche indirizzato verso un'analisi delle influenze che essa può avere sul linguaggio e sull'espressione, in particolare per quanto riguarda l'espressione del non-stabile.

2 Le tre discipline che vengono prese in esame sono la filosofia, la storia e la critica; pur essendo il testo suddiviso in tre parti che corrispondono a questi tre temi, l'autore si premura di dirci che nella sua analisi essi non sono separati, bensì tenuti insieme.

Il testo si apre con il capitolo «Le penser littéraire» (pp. 5-10), una sorta di introduzione nella quale Dubreuil ci espone la propria “poetica” e ci presenta il piano dell'opera: «Je veux modifier la lecture régulée des œuvres que je commente, tout en avançant dans mon propos sur la ruine du concept, sur les inévitables glissements du nom de l'histoire, sur l'état critique où se met - et nous met - la littérature lorsqu'elle répond aux autres discours» (p. 10). 
4 La prima parte, quella più filosofica, si intitola appunto La ruine du concept, e mira ad attribuire alla letteratura una sorta di ruolo di decostruzione della filosofia, o comunque di una filosofia chiusa in se stessa, una "filosofia-tempio". Ecco perché, allora, il primo capitolo è «Le temple: Nerval» (pp. 15-39), e in esso Sylvie viene letta come emblema di una letteratura che sia "rovina", "conflagrazione" della parola filosofica. Se Nerval si rifà a Rousseau, Genet si immette sulla scia di Descartes. «Une palinodie du philosophique: Genet» (pp. 41-57) studia il Journal du voleur come decostruzione dell'idea di concetto filosofico, dando alla parola letteraria il potere di assumere su di sé la contraddizione, la non-identità, tramite la dimensione del solitario, di un io che, grazie alla scrittura, si fa monade «qui contient la totalité inhumaine et se confond avec elle» (p. 55). L'ultimo capitolo di questa prima parte è «L'écart du savoir: Maupassant» (pp. 59-76). Tutta l'opera di questo scrittore mira a far coesistere il letterario ed il filosofico all'interno dei testi, mettendo in evidenza i limiti del secondo grazie all'esplorazione di una dimensione fantastica che va oltre il razionale e la logica.

5 La seconda parte è intitolata Le nom de l'histoire, ed il primo capitolo è «Le signe du révolu: Baudelaire» (pp. 81-102), nel quale l'autore studia Le cygne per esprimere l'idea che la storia letteraria deve abbandonare la sua pretesa di totalità per assumere su di sé la coscienza della propria discontinuità. Seguono "Comme une hantise: Sartre» (pp.105-122), nel quale la storia letteraria viene necessariamente vista come "in situazione", e nel quale Dubreuil vede buona parte dell'opera sartreana come un tentativo di fuga dal fantasma di Kafka; e «Projets et totalité: Bataille» (pp. 123-152), dove si studiano i commenti, le critiche e i punti cardine di quella che è, per Bataille, la storia universale.

6 L'ultima parte (La vie de l'œuvre), che prende in esame la critica, è incentrata su Proust, Artaud e, ancora una volta, Nerval. In «Hypercritique: Proust» (pp. 157-172) viene studiato come «la progressive transformation du Contre Sainte-Beuve en la Recherche permettra de poser l'hypothèse d'une intensité hypercritique qui n'est pas purement adventice à la littérature, mais en forme de nécessité» (p. 156); per quanto riguarda «Vérifier l'intensité: Artaud» (pp. 173-188), vengono presi in esame gli ultimi anni di quest'autore, durante i quali egli si è costantemente applicato - allo stesso tempo - ad una critica della critica, ma anche ad una critica verso se stesso (l'unica critica possibile, secondo lui); infine «La théorie composite: Nerval» (pp. 189-205) analizza Aurélia come una sorta di mise en œuvre, di rilettura e armonizzazione di tutta l'opera nervaliana.

7 Quello che traspare da questi saggi è l'idea di una letteratura che, portandosi ai limiti estremi di discipline come filosofia, storia, critica, debba metterne in crisi i principi costitutivi, esplicitandone le mancanze, gli scacchi, e farle implodere su se stesse, ma al fine di un ripensamento delle proprie caratteristiche che le porti ad una ricostituzione più consapevole. 